\title{
PENERAPAN ALGORITMA FAST FOURIER TRANSFORM (FFT) PADA PROTOTYPE DOOR LOCK SYSTEM BERBASIS VOICE RECOGNITION
}

\section{The Application of the Fast Fourier Transform (FFT) Algorithm to the Voice Recognition Based Door Lock Prototype System}

\author{
Fery Tobing, ferytobing94@gmail.com ${ }^{1)}$, Halim Agung, hagung@ bundamulia.ac.id ${ }^{2)}$ \\ ${ }^{1) 2)}$ Teknik Informatika, Fakultas Teknologi dan Desain, Universitas Bunda Mulia
}

\begin{abstract}
Biometric identification is one of the media in the operation of home automation systems that are in great demand. This is because conventional identification such as the use of PINs, passwords, cards and keys is not reliable enough, in terms of security and how to operate them. The method used in this study is the Fast Fourier Transform (FFT) method which consists of system analysis, design, implementation and testing. This study uses 3 (three) words used for voice commands, namely "Open" and "Lock" or "Close". The word "unlock" is used to open the door lock solenoid, the word "lock" is used to lock the door lock solenoid, while the word "close" is only an alternative when the word "lock" is not detected by the sound sensor due to various factors such as noise around the appliance, bad pronunciation. Where in the future can use another version of the sound sensor to be applied to the prototype door lock system based on voice recognition.
\end{abstract}

Keywords: voice recognition, home automation, FFT, prototype, solenoid door lock

\begin{abstract}
ABSTRAK
Identifikasi biometrik merupakan salah satu media pada pengoperasian sistem home automation yang banyak diminati. Hal ini karena identifikasi konvensional seperti penggunaan PIN, password, kartu dan kunci sudah tidak cukup handal, dari segi keamanan dan cara pengoperasiannya. Metode yang digunakan dalam penelitian ini ada metode Fast Fourier Transform (FFT) yang terdiri dari analisis sistem, perancangan, implementasi dan pengujian. Penelitian ini menggunakan 3 (tiga) kata yang digunakan untuk perintah suara yaitu "Buka" dan "Kunci" atau "Tutup". Kata "Buka" digunakan untuk membuka solenoid door lock, kata "Kunci" digunakan untuk mengunci solenoid door lock, sedangkan kata "Tutup" hanya sebagai alternatif ketika kata "Kunci" tidak terdeteksi oleh sensor suara yang dikarenakan berbagai faktor seperti kebisingan yang ada disekitar alat, pelafalan yang kurang baik. Dimana untuk kedepannya dapat menggunakan sensor suara versi lain untuk diaplikasikan ke prototype door lock system berbasis voice recognition.
\end{abstract}

Keywords: voice recognition, home automation, FFT, prototype, solenoid door lock

\section{PENDAHULUAN}

Identifikasi biometrik merupakan salah satu media pada pengoperasian sistem home automation yang banyak diminati [1]. Hal ini karena identifikasi konvensional seperti penggunaan PIN, password, kartu dan kunci sudah tidak cukup handal, dari segi keamanan dan cara pengoperasiannya [2]. Biometrik pada dasarnya merupakan pengenalan seseorang berdasarkan kepribadian unik yang dimiliki setiap orang seperti pengenalan wajah, sidik jari, pengenalan suara, pengenalan retina, dan tanda tangan [3]. 
Pengenalan suara bekerja dengan menganalisis fitur suara antar individu, setiap orang memiliki pola suara unik yang berasal dari pola anatomi mereka (ukuran serta bentuk mulut dan tenggorokan) dan pola perilaku (nada suara, gaya, aksen bicara) [4] [5]. Pengoperasian sistem ini sangat mudah dan tidak memerlukan energi yang banyak, hal tersebut yang menjadi alasan pengenalan suara sangat cocok digunakan sebagai media pengoperasian home automation. pengenalan suara yaitu voice recognition dan speech recognition. Voice recognition berbeda dengan speech recognition, voice recognition membantu pengguna untuk mencocokkan suara dengan suara pengguna yang telah divalidasi sebelumnya, dan memverifikasi kecocokkan suara tersebut sehingga memenuhi syarat identifikasi biometrik [6]. Oleh karena itu voice recognition cocok digunakan sebagai pengontrol pintu, karena berkaitan dengan integritas pengguna yang diizinkan untuk mengakses pintu [7].

Penelitian terdahulu yang menggunakan modul Easy VR 3.0 sebagai pengenalan suara untuk mengontrol peralatan rumah yaitu sebagai kontrol untuk menghidupkan dan mematikan kipas angin dan lampu. Pada penelitian tersebut kata yang digunakan sebagai kode adalah "Action", "Down", "One" [8]. Pada penelitian ini dengan judul "PENERAPAN

ALGORITMA FAST FOURIER
TRANSFORM (FFT) PADA PROTOTYPE DOOR LOCK SYSTEM BERBASIS VOICE RECOGNITION" menggunakan modul Easy VR 3.0 sebagai modul pengenalan suaranya dan digunakan kata "Buka" untuk kode membuka pengunci pintu, serta kata "Kunci" atau "Tutup" untuk menutup pengunci pintu.

\section{LANDASAN TEORI}

Pengenalan ucapan atau pengenalan suara dalam istilah bahasa Inggrisnya, voice recognition adalah suatu pengembangan teknik dan sistem yang memungkinkan komputer untuk menerima masukan berupa kata yang diucapkan. Teknologi ini memungkinkan suatu perangkat untuk mengenali dan memahami kata - kata yang diucapkan dengan cara digitalisasi kata dan mencocokkan sinyal digital tersebut dengan suatu pola tertentu yang tersimpan dalam suatu perangkat. Kata - kata yang diucapkan diubah bentuknya menjadi sinyal digital dengan cara mengubah gelombang suara menjadi sekumpulan angka yang kemudian disesuaikan dengan kode - kode tertentu untuk mengidentifikasikan kata kata tersebut. Hasil dari identifikasi kata yang diucapkan dapat ditampilkan dalam bentuk tulisan atau dapat dibaca oleh perangkat teknologi sebagai sebuah komando untuk melakukan suatu pekerjaan, misalnya penekanan tombol pada telepon genggam yang dilakukan secara otomatis dengan komando suara. Maka dari itu penulis membangun sebuah prototype door lock system berbasis voice recognition.

Alat pengenal ucapan / suara, yang sering disebut dengan voice recognizer, membutuhkan sampel kata sebenarnya yang diucapkan dari pengguna. Sampel kata akan didigitalisasi, disimpan dalam komputer, dan kemudian digunakan sebagai basis data dalam mencocokkan kata yang diucapkan selanjutnya. Sebagian besar alat pengenal ucapan sifatnya masih tergantung kepada pembicara. Alat ini hanya dapat mengenal kata yang diucapkan dari satu atau dua orang saja dan hanya bisa mengenal kata kata terpisah, yaitu kata - kata yang dalam penyampaiannya terdapat jeda antar kata.

FFT adalah algoritma untuk menghitung Discreate Fourier Transform (DFT) dengan cepat dan efisien [9]. Perhitungan DFT secara langsung membutuhkan operasi aritmatika sebanyak $0\left(\mathrm{~N}_{2}\right)$ atau mempunyai orde $\mathrm{N}_{2}$, sedangkan perhitungan best case dengan FFT akan membutuhkan operasi sebanyak $0(\mathrm{~N} \log \mathrm{N})$. DFT dinyatakan dalam persamaan (1).

$$
X n=\sum_{r=0}^{N-1} x_{r} W^{r n}
$$


Persamaan $\mathrm{N}$ dibagi 2, maka penjumlahan pada dapat dibagi menjadi 2 yaitu penjumlahan dalam bentuk $\mathrm{r}$ genap dan untuk r ganjil. $D F T$ untuk r genap yaitu $\left\{\mathrm{X}_{0}, \mathrm{X}_{2}, \ldots \mathrm{X}(\mathrm{N}-2)\right\}$ dan ditulis sebagai persamaan (2)

$$
E n=\sum_{r=0}^{N / 2-1} x_{2 r} W^{2 r n}
$$

DFT untuk r ganjil yaitu $\left\{\mathrm{X}_{1}, \mathrm{X}_{3}\right.$, ... $\mathrm{X}(\mathrm{N}-1)\}$ dan ditulis sebagai persamaan (3).

$$
O n=\sum_{r=0}^{N / 2-1} x_{(2 r+1)} W^{(2 r+1) n}
$$

$D F T$ dalam deret sebanyak $\mathrm{N}$ dapat dinyatakan dengan dua DFT dalam deret sebanyak $\mathrm{N}$ dibagi 2. Pada persamaan (4)

$$
X_{n} \mid=E_{n}+W^{n} O_{n}
$$

Dengan cara ini, maka untuk mencari spektrum sinyal tertentu diperlukan sebanyak $2 \mathrm{x}(\mathrm{N} / 2)^{2}=2 \mathrm{xN}^{2} / 4=\mathrm{N}^{2} / 2$ perkalian. Jika memperhitungkan perkalian dengan maka jumlah perkalian yang harus dilakukan adalah $\mathrm{N}^{2} / 2+\mathrm{N}$. Dengan asumsi $\mathrm{N} \ll \mathrm{N}^{2}$, maka dapat dinyatakan jumlah perkalian yang dibutuhkan adalah dalam orde $\mathrm{N}^{2} / 2$ atau $\mathrm{O}\left(\mathrm{N}^{2} / 2\right)$ yaitu setengah jumlah perkalian yang diperlukan jika digunakan cara lama.

Jika N/2 dapat dibagi 2, maka dapat dinyatakan DFT N/2 titik masing - masing dengan 2 DFT N/4 titik. Hasilnya pengurangan jumlah perkalian yang lebih banyak lagi.

Jika $\mathrm{N}=2^{\mathrm{M}}(\mathrm{M}$ disebut radiks $)$ maka prosedur diatas dapat dilakukan berulang - ulang hingga sampai pada DFT 1 titik yaitu $\mathrm{X}_{0}=\mathrm{X}_{0}$ yang berarti tidak diperlukan perkalian.

Dengan $\mathrm{N}=2^{\mathrm{M}}$ maka berarti ada $\mathrm{M}$ tingkat dimana $\mathrm{M}=\log _{2} \mathrm{~N}$ pada setiap tingkat harus ada $\mathrm{N}$ perkalian, maka algoritma memerlukan $\mathrm{N} \log _{2} \mathrm{~N}$ perkalian.
Keuntungan menggunakan FFT dibandingkan DFT pada persamaan (5).

$$
\frac{N^{2}}{N \log _{2} N}=\frac{N}{M}
$$

\section{METODOLOGI PENELITIAN}

Berikut ini akan dijabarkan rancangan dari setiap pin - pin sensor yang terhubung ke Arduino Uno, yg dimana Arduino Uno saya gunakan sebagai master untuk mengirimkan data suara dan

\begin{tabular}{|c|c|}
\hline \multicolumn{2}{|r|}{ Arduino Uno } \\
\hline Pin & Sensor \\
\hline GND & $\begin{array}{c}\text { Relay, Jumper; Jumper, } \\
\text { Ultrasonik, Jumper, LCD } 16 \times 2 \text {, } \\
\text { Easy VR } 3.0\end{array}$ \\
\hline $5 \mathrm{~V}$ & $\begin{array}{c}\text { Relay, Easy VR 3.0, Ultrasonik, } \\
\text { Jumper, } L C D \quad 16 \times 2\end{array}$ \\
\hline $\mathrm{A} 4$ & $L C D 16 \times 2$ \\
\hline A5 & $L C D 16 \times 2$ \\
\hline D13 & Easy VR 3.0 \\
\hline D12 & Easy VR 3.0 \\
\hline D10 & Jumper \\
\hline D9 & Ultrasonik \\
\hline D8 & Ultrasonik \\
\hline D7 & Relay \\
\hline
\end{tabular}
menerima perintah untuk membuka door lock system.

Tabel 1. Pin Arduino Uno

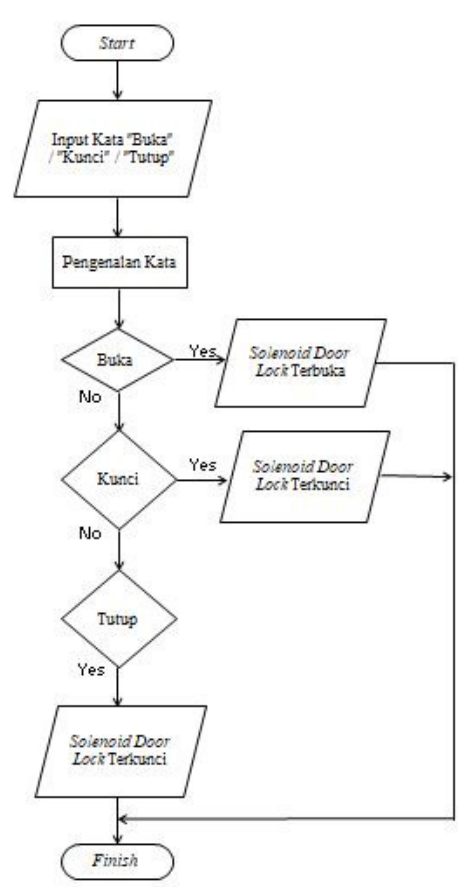

Gambar 1. Flowchart Prototype Door Lock System 
Perancangan flowchart diagram bertujuan untuk menggambarkan aliran proses sistem secara rinci mulai dari awal sampai akhir. Flowchart diagram prototype door lock system ditunjukan pada Gambar 1 .

Pada Gambar 1. dijelaskan flowchart prototype door lock system menggunakan voice recognition yang menggunakan sensor Easy VR 3.0 sebagai sensor penginputan suara. Pada gambar dijelaskan bahwa saat user melalukan input kata berupa suara "Buka" atau "Kunci" atau "Tutup", maka sistem akan melakukan pengenalan suara yang diproses dengan algoritma Fast Fourier Transform. Jika sistem mengenali bahwa itu berupa suara "Buka" maka solenoid door lock akan membuka pengunci pintu. Jika berupa suara "Kunci" atau "Tutup" maka solenoid door lock akan mengunci pengunci pintu. Dan apabila ada input-an suara di luar kata "Buka" dan "Kunci" atau "Tutup" maka sistem tidak dapat berkerja atau tidak akan melakukan aktivitas apapun.

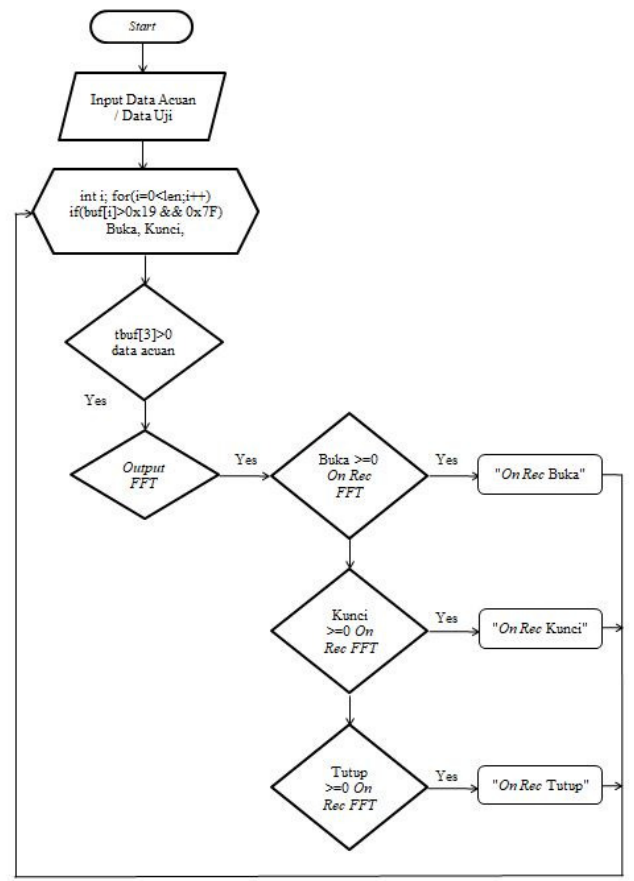

Gambar 2.Flowchart Fast Fourier Transform (FFT)
Pada Gambar 2 dijelaskan flowchart dari fast fourier transform untuk pengenalan suara "Buka" dan "Kunci" atau "Tutup" pada prototype door lock system, pertama algoritma akan meng-input-kan data uji / data acuan lalu algoritma memproses data uji yang di konversikan dengan bilangan heksadesimal untuk di ubah menjadi kata - kata, jika suara tidak dikenali maka akan langsung ke output dan selesai, jika suara dikenali maka algoritma akan memproses sesuai kata yang kita instruksikan lalu setelah proses selesai akan kembali ke data acuan untuk di cek kembali perintah selanjutnya yang akan diinstruksikan.

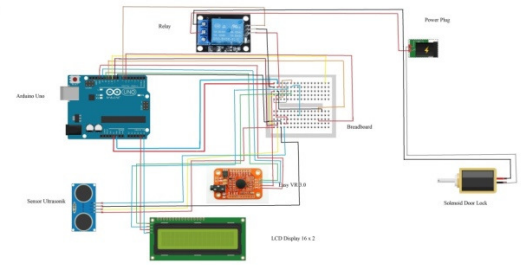

Gambar 3. Schematic Diagram Prototype

Pada Gambar 3 adalah Schematic Diagram dari prototype yang telah dibuat yaitu door lock system. Komponen yang digunakan berupa Breadboard, Arduino Uno, Sensor Easy VR 3.0, Sensor Ultrasonik, Relay , LCD Display 16 x 2, Power Plug dan Solenoid Door Lock.

Pada Gambar 3 adalah rangkaian seluruh prototype door lock yang menggunakan sensor suara berbasis mikrokontroler. Setiap komponen membutuhkan energi listrik yang mempunyai pin VCC dan GND, fungsi dari kedua pin ini adalah untuk mengalirkan arus ke komponen - komponen yang terhubung. Anoda dan Katoda itu sendiri yaitu arus listrik yang berlawanan yang dilambangkan dengan symbol (+) dan (-), Anoda merupakan nama lain dari VCC yang berarti listrik positif, VCC sendiri harus mendapat arus + , VCC biasa memiliki tegangan antara 3,3 Volt - 5 Volt dan Katoda nama lain dari GND yang berarti listik negatif dan harus mendapat arus atau dalam hal hanya teradapat 2 kaki, GND sendiri adalah bagian minusnya. Semua informasi dan data disalurkan 
melalui mainboard untuk menjalankan perintah yang telah dibuat, sehingga masing - masing komponen dapat bekerja dengan baik di setiap perintahnya.

\section{HASIL DAN PEMBAHASAN}

Pada Gambar 4 merupakan tampilan spektrum suara dengan kata "Buka" dan suara yang dikeluarkan memiliki frekuensi sekitar 746,9 Hz. Dengan keadaan seperti ini maka modul sensor suara Easy Voice Recognition dapat memproses suara dengan kata "Buka" untuk membuat solenoid door lock terbuka.
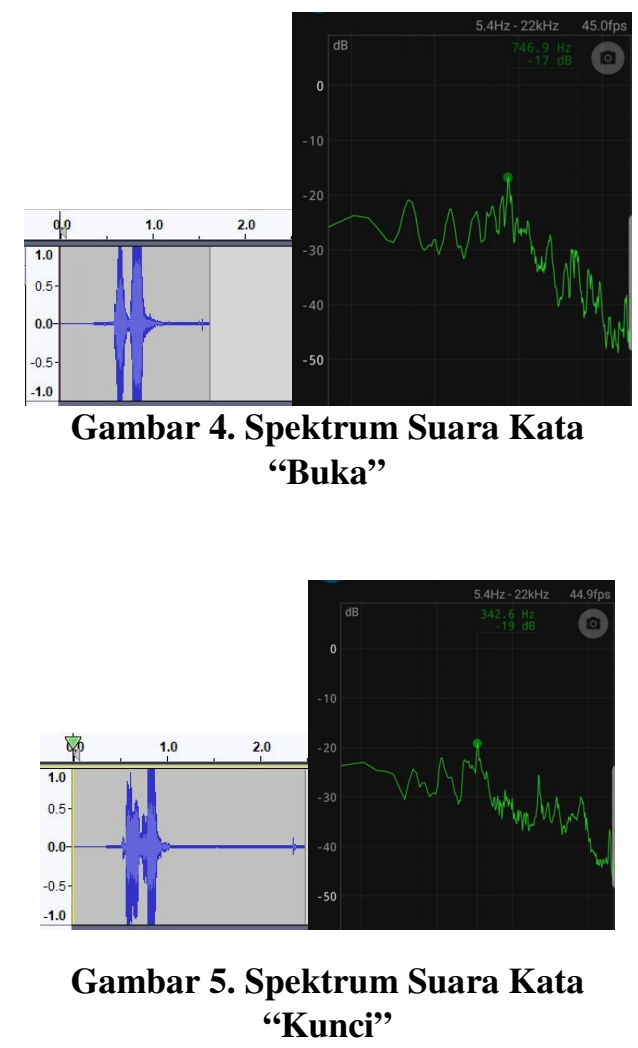

Pada Gambar 5 merupakan tampilan spektrum suara dengan kata "Kunci" dan suara yang dikeluarkan memiliki frekuensi sekitar 342,6 Hz. Dengan keadaan seperti ini maka modul sensor suara Easy Voice Recognition dapat memproses suara dengan kata "Kunci" untuk membuat solenoid door lock terkunci.

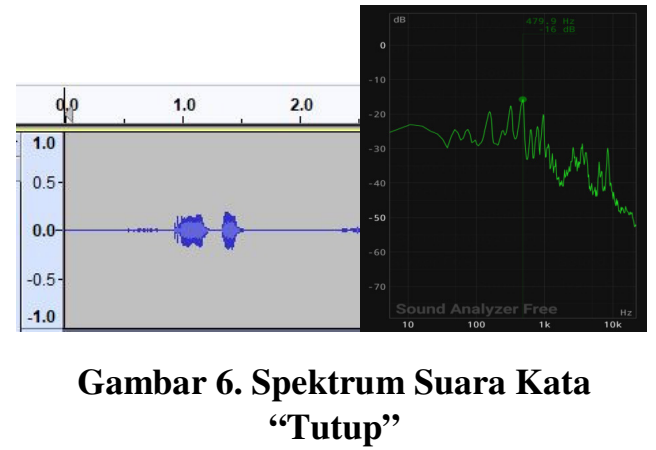

Pada Gambar 6 merupakan tampilan spektrum suara dengan kata "Tutup" dan suara yang dikeluarkan memiliki frekuensi sekitar 479,9 $\mathrm{Hz}$. Dengan keadaan seperti ini maka modul sensor suara Easy Voice Recognition dapat memproses suara dengan kata "Tutup" untuk membuat solenoid door lock terkunci.

Dari beberapa sampel suara yang telah di ambil melalui proses training suara akan dihitung menggunakan rumus Ecludian Distance (pengukuran jarak) yang dirumuskan sebagai pada persamaan(6)

$$
d v(x 1-y 1)^{2}+(x 2-y 2)^{2}=z
$$

Ket $: \mathrm{x}=$ nilai gelombang pertama yang ditangkap oleh microphone. $\mathrm{y}=$ nilai gelombang kedua yang ditangkap oleh microphone.

Tabel 2. Tabel Perhitungan Jarak Suara Dengan Microphone

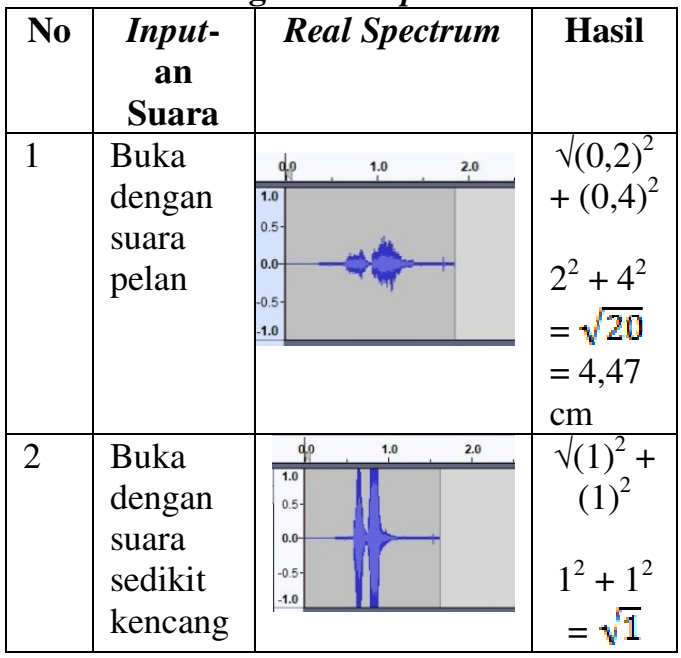




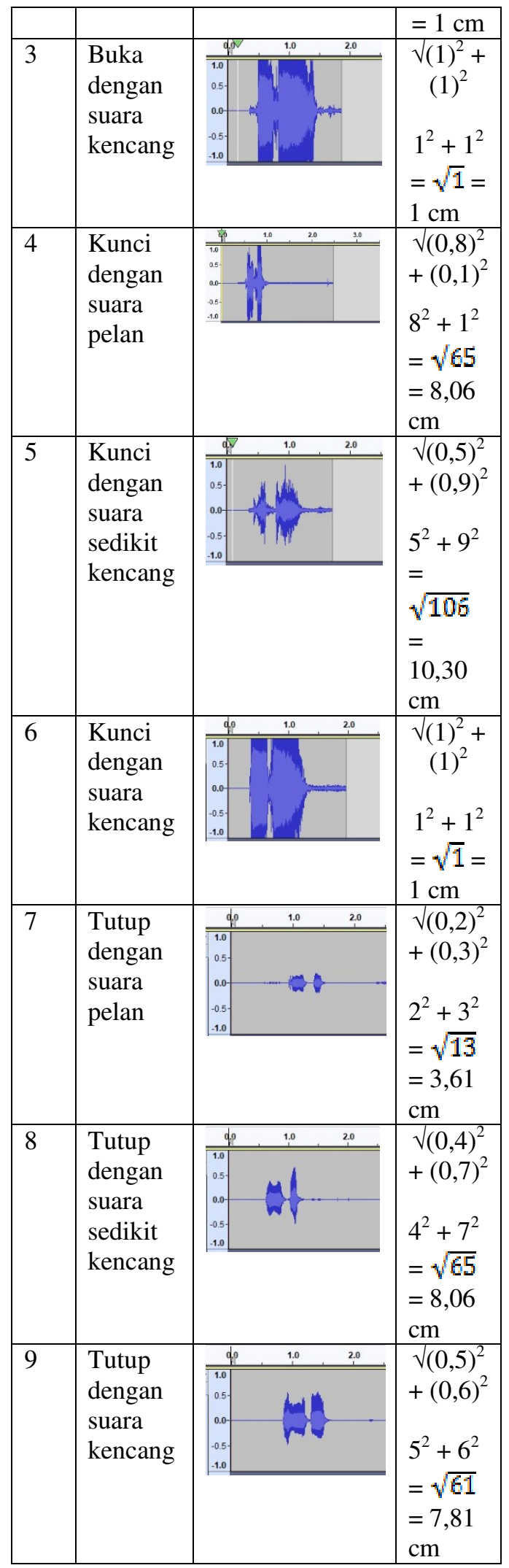

Pada Tabel 2 dijelaskan perhitungan jarak dari suara asli dengan menggunakan Ecludian Distance yang di mana dari beberapa sample suara diambil nilai - nilai paling kecil untuk di jadikan nilai acuan yaitu untuk kata "Buka" mendapat nilai sebesar $1 \mathrm{~cm}$ sampai 4,47 $\mathrm{cm}$, kata "Kunci" sebesar $1 \mathrm{~cm}$ sampai $10,30 \mathrm{~cm}$ dan untuk kata "Tutup" mendapat nilai sebesar 3,61 cm sampai $8,06 \mathrm{~cm}$.

\section{SIMPULAN}

Berdasarkan hasil penelitian yang telah dilakukan dapat ditarik kesimpulan untuk penelitian ini adalah sebagai berikut :

Kata "Buka" digunakan untuk membuka solenoid door lock, kata "Kunci" digunakan untuk mengunci solenoid door lock, sedangkan kata "Tutup" hanya sebagai alternatif ketika kata "Kunci" tidak terdeteksi oleh sensor suara. Keberhasilan pengenalan suara dengan kata "Buka" dan "Kunci" atau "Tutup" dengan menggunakan algoritma Fast Fourier Transform mendapatkan nilai persentase yang berhasil dikenali sebesar 33\% di tempat hening, $1,33 \%$ di tempat agak ramai, dan $0 \%$ ditempat yang ramai, sehingga dapat disimpulkan bahwa tingkat kebisingan lingkungan disekitar mempengaruhi tingkat keberhasilan prototype menangkap sinyal suara yang diberikan, toleransi kegagalan prototype sebesar 20\% di tempat hening, 30\% di tempat agak ramai, $40 \%$ di tempat ramai.

\section{DAFTAR PUSTAKA}

[1] Imario, Anjar, Sudiharto, Dodi Isaksono and Ariyanto, Endro. "The validated voice recognition measurement of several tribes in Indonesia using easy VR 3.0. Case study : The prototype of automated doors." Semarang : IEEE, 2017, 2017 International Seminar on Application for Technology of Information and Communication (iSemantic), $132 \quad-\quad 136$. 
[DOI: 10.1109/ISEMANTIC.2017. 8251857]

[2] Tumuli, Andika D.L., Najoan, Xaverius N. and Sambul, Alwin M. "Implementasi Teknologi Biometrical Identification untuk Login Hotspot." 2017, E-Journal Teknik Informatika, 12 (1), 1 - 5. [ISSN : 2301 - 8364]

[3] Srivastava, Himanshu. "A Comparison Based Study on Biometrics for Human Recognition". 2013, IOSR Journal of Computer Engineering (IOSR $J C E), 15$ (1), 22 - 29. [e-ISSN : 2278 - 0661] [p- ISSN : 2278 8727]

[4] Frischholz, Robert W. and Dieckmann, Ulrich. BioID : "A Multimodal Biometric Identification System". s.1. : IEEE, 2000. 64 - 68. [DOI : 10.1109/2.820041]

[5] King, Rawlson O'Neil. "Speech and Voice Recognition. Biometrics Research Group". (Online) 2014. (https://www.biometricupdate.com/ wpcontent/uploads/2014/05/VoiceBiometrics.pdf), diakses pada tanggal 27 November 2019, 17:49

[6] Saini, Preeti and Kaur, Parneet. "Automatic Speech Recognition : A Review". 2013, International Journal of Engineering Trends and Technology, 4. [ISSN : 2231-5381]

[7] Maiwald, Eric and Sieglein, William. "Security Planning and Disaster Recovery 1st Edition". California : McGraw - Hill, 2002. [ISBN : 0-07-222463-0]

[8] Hasan, Nurul Fadzilah, Rejab, Mohd R.M. and Sapar, Nurul Hidayah. "Implementation of speech recognition home control system using Arduino". 2015, ARPN Journal of Engineering and Applied Sciences, 10 (23), 17492 17498. [ISSN : 1819 - 6608]

[9] Radiana, S.G., 2008, "Discreate Fourier Transform Menjadi Fast Fourier Transform", Jurusan Teknik Elektro, UGM Yogyakarta. (Online).

(http://te.ugm.ac.id/ risanuri/isyara tsystem/paperDFTkeFFT.pdf), diakses pada tanggal 27 November 2019, 18:19

[10] Bushberg, Jerrold, T., 2002, "The Essential Physics of Medical Imaging". California : Lippincott Williams \& Wilkins. (Buku)

[11] Depdiknas, 2013, "Materi Pokok Fisika Efek Doppler 2008". Pustekkom Depdiknas. (Online). (http://sumberbelajar.belajar.kemdi kbud.go.id/), diakses pada tanggal 27 November 2019, 18:36

[12] Giancoli, D., 2001, "Fisika Edisi Kelima, Jilid 1", Erlangga, Jakarta. (Buku)

[13] Harcarik, T. Bocko, J dan Maslakova, K., 2012, "Frequency Analysis of Acoustic Signal Using The Fast Fourier Transformation In Matlab", Jurnal, University of Kosice, Slovakia. [DOI : 10.1016/j.proeng.2012.09.505]

[14] Susilawati, I., 2009, "Transformasi Fourier Cepat", Teknik Elektro, Fakultas Teknik dan Ilmu Komputer, Universitas Mercu Buana, Yogyakarta. (Online). (https://www.yumpu.com/id/docum ent/read/17889967/transformasifourier-cepat), diakses pada tanggal 27 November 2019, 18:43 